\title{
Analysis of PI Controllers with Anti-Windup Techniques on Level Systems
}

\author{
K. C. C. MARIQUITO \\ CEFET-MG \\ Department of Eletroelectronics \\ José Peres Street, 558, Leopoldina \\ BRAZIL
}

\author{
G. A. MACHARETH \\ CEFET-MG \\ Department of Eletroelectronics \\ José Peres Street, 558, Leopoldina \\ BRAZIL
}

\author{
M. F. SANTOS \\ CEFET-MG \\ Department of Eletroelectronics \\ José Peres Street, 558, Leopoldina \\ BRAZIL
}

\author{
P. MERCORELLI \\ Leuphana University of Lüneburg \\ Institute of Product and Process Innovation \\ D-21335, Lüneburg \\ GERMANY
}

\author{
L. G. ROCHA \\ CEFET-MG \\ Department of Eletroelectronics \\ José Peres Street, 558, Leopoldina \\ BRAZIL
}

\begin{abstract}
The actuator element saturation for a long period of time can force high overshoot peaks in the physical system, in most cases, due to the integral action. Taking this effect into consideration, this work aims to present a case study considering this situation applied on a SMAR didactic level system, where an Anti-Windup Technique (AWT) with 5 distinct classic Proportional-Integral (PI) controllers were implemented. To validate its effectiveness, the results were always presented with the comparison of the use with and without AWT controlled responses. Also, the tests were carried out through implementations in MATLAB software, where the results showed a high necessity to use AWTs in these kind of systems. As for the controller's tuning method efficiency, the integral of squarederrorindexprovedthattheCohen-CoonandZiegler-Nicholscontrollersshowedbetterresults.
\end{abstract}

Key-Words: Anti-windup Techniques, PI Controllers, Level System Identification.

Received: October 29, 2019. Revised: April 7, 2020. Accepted: April 26, 2020. Published: May 5, 2020.

\section{Introduction}

Currently, industrial processes use tanks coupled for several desired functions, such as transport and storage of liquids, which makes level systems to be highly prominent in the engineering industries and an important part of current production processes. Also, they are often operated in the petrochemical, pulp and paper and water and affluent treatment industries [1].

However, the liquid level control becomes an interesting problem in the industry, as they need the tanks to be coupled to each other interacting between them, also requiring a regulatory control of flow in and out. An important purpose for this control is to keep the level as close as possible to the Set Point (SP). Taking Proportional-Integral (PI) controller into account, which is still often used in industry, the controller must contain the integral action, enabling null stationary errors. About the proportional action, the system immediately react to the error, giving a fast reaction to disturbances or variations in the SP [2].

When a full-action controller is used, the system error continues to be integrated and the integral term tends to become large, causing high overshoots in the controlled responses, which is critical when the actuator is saturated for a long period of time. Thus, to make the controller returning to the operating in the linear region, it is necessary to minimize this integral part, which is the main characteristic of the AntiWindup Technique (AWT). This, in turn, uses the actuator saturation to create a difference between its input and output signals, being subsequently feedback into the integral loop. Without saturation, this technique has no effect on the system, resulting in operation within the linear region [1].

A brief survey highlights some interesting works: authors [3] show the use of a PI controller tested on a stepper motor together with AWTs, being developed to achieve a faster response to speed with betterSP tracking. After the controller application, its results were compared with a conventional PI controller and it was concluded that the AWT was strictly necessary to increase the control loop efficiency.

The study done in [4] presents a comparison regarding the speed response of a BLDC (Brushless Di- 
rect Current Motors) motor using the conventional PI controller with and without AWT and the fuzzy controller. These controllers were applied for different load and speed conditions, and finally, after comparing their results, it was possible to verify that the conventional PI controller showed a slower response, while the PI controller with AWT demonstrated the opposite situation, more suitable for the BLDC motor activation during its variations, considering the conditions tested by the authors.

As a last example of application, work [5] reported the development of an AWT for proportional resonance controllers in the current control circuit of a voltage source converter with a filter. By controlling the feedback signal distribution for each integrator input, it is possible to effectively adjust the phase change caused by these signals, corresponding to the $\mathrm{SP}$ signal. The performance evaluation of the proposed scheme was obtained by simulation comparing it with the existing techniques for the respective converter connected to the grid. Finally, it was demonstrated that the proposed scheme produced a lower power factor and lower current distortion. More related works about similar level control systems are found in $[6,7,8,9]$.

This work aims to apply an AWT advised to be the most efficient for the level system presented in [1], also to make efficiency comparisons with and without the technique, among 5 types of classical PI controllers: Ziegler-Nichols; Cohen-Coon; Haalman; Chien, Hrones and Reswick to $0 \%$ and $20 \%$ of overshoot. For this, it was necessary to perform the system identification, approaching it for First Order Plus Dead Time (FOPDT) system, using the 3 parameters methods of Bröida [10], Smith [11] and Vitečkovà [12].

This work is divided as follows: Section 2 presents the didactic industrial plant used, as well as its physical structure and functioning explained. Also, in this section, the identification methods applied to the plant are also presented. Right after in Section 3, the classic control techniques used are presented: Cohen Coon, Ziegler Nichols, Haalman and CHR (Chien, Hrones and Reswick) with 0 and $20 \%$ of overshoot. Section 4 shows the controller topology with AWT. Subsequently, Section 5 presents the experimental results. Finally, Section 6 shows the conclusions and some future works.

\section{System of Study}

\subsection{Didactic Plant}

All experimental tests were performed based on the didactic plant model PD3 (SMAR), shown in Fig. 1.

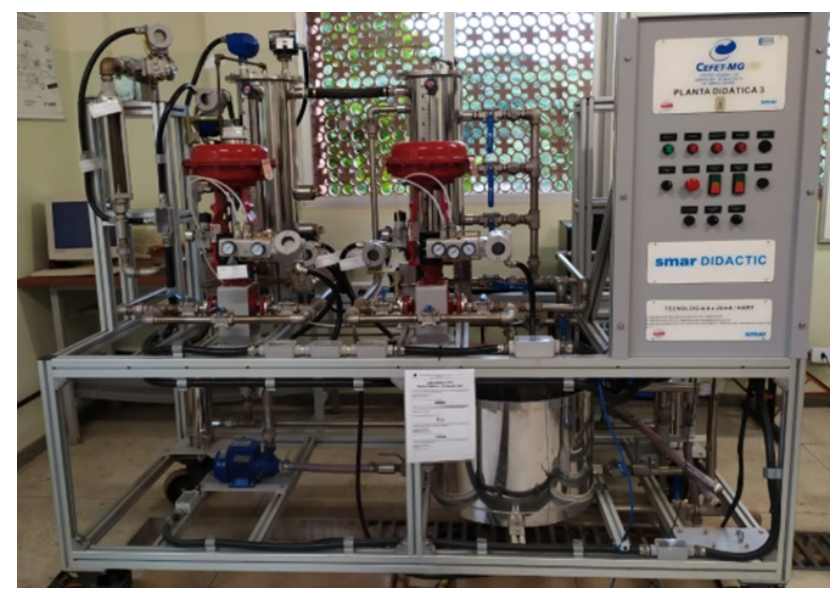

Figure 1: Didactic plant PD3 SMAR.

In the level system shown in Fig. 1 is possible to see how measurements are performed by an LD302 differential transmitter, based on hydrostatic principles. Thus, a steady state system in open or closed loop uses the Mass Preservation Law, where the liquid level stability causes a direct relationship between the pneumatic control valve opening and the outlet flow, simulating or consuming and the disturbances present in the industrial field [13].

From the displayed plant, it is possible to work with three important variables of control systems in industrial processes: flow, temperature and level (used in this study).

The control system studied here consists of a reservoir (where the water is stored), an electric pump (conducts the fluid to a control tank), a pneumatic valve (the actuator which controls the flow varying between $0 \%$ and $100 \%$ ), a control tank (where this liquid is controlled), and also the level sensor. The Fig. 2 presents a simplified schematic diagram of the aforementioned components.

From the clearly illustrated figure above, the pump is responsible for transporting the fluid from the storage tank to the control tank, passing through the pneumatic valve. Also, at the control tank outlet, there is a manual valve that simulates the liquid consumption, returning it to the storage tank and consequently ending the cycle.

In addition, Fig. 3 presents a wider illustration of level tank system communication from the computer to the plant, which consequently communicates to its instruments. 


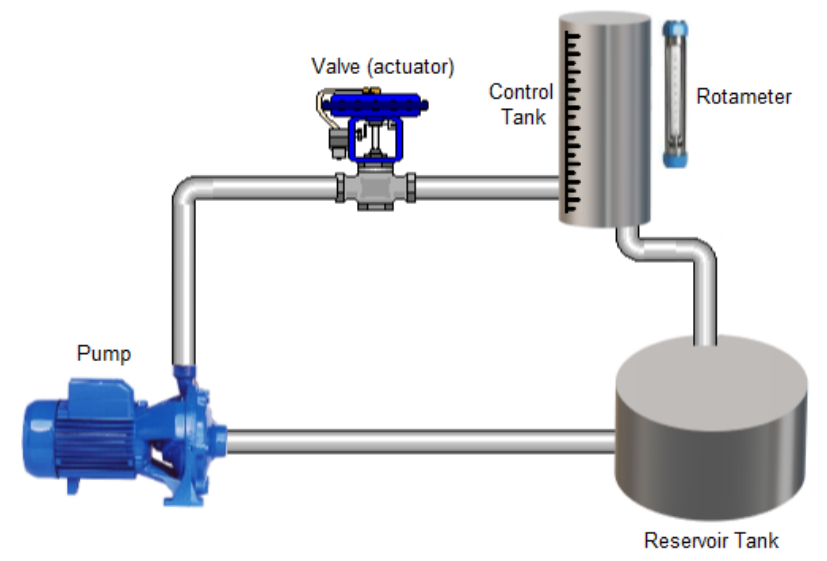

Figure 2: Simplified schematic diagram of the study plant.

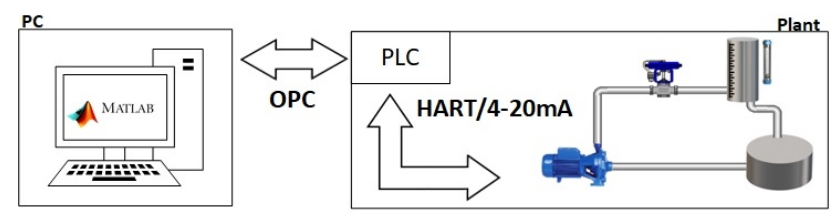

Figure 3: Overall illustration of the entire system, including the computer running Matlab.

The Matlab software runs at the computer, which communicates to the level plant through the OPC (OLE for Process Control) protocol via LC700 PLC (Programmable Logic Controller), coupled at the plant. The PLC, in turn, communicates to the plant instruments via HART (Highway Addressable Remote Transducer)/4-20mA protocol. It is important to highlight that the controlled variable in the Matlab environment is an after processing signal variable, run before reach the computer.

\subsection{System Identification Methods}

Firstly, the open loop process identification was carried out, which considers a direct relationship between the system flow in and out.

After the data gathering, 3 identification methods were used: Bröida, Smith and Vitečkovà. Figure 4 shows the respective curves obtained. Also, through the Integral of the Square Error (ISE) index, Table 1 is presented.

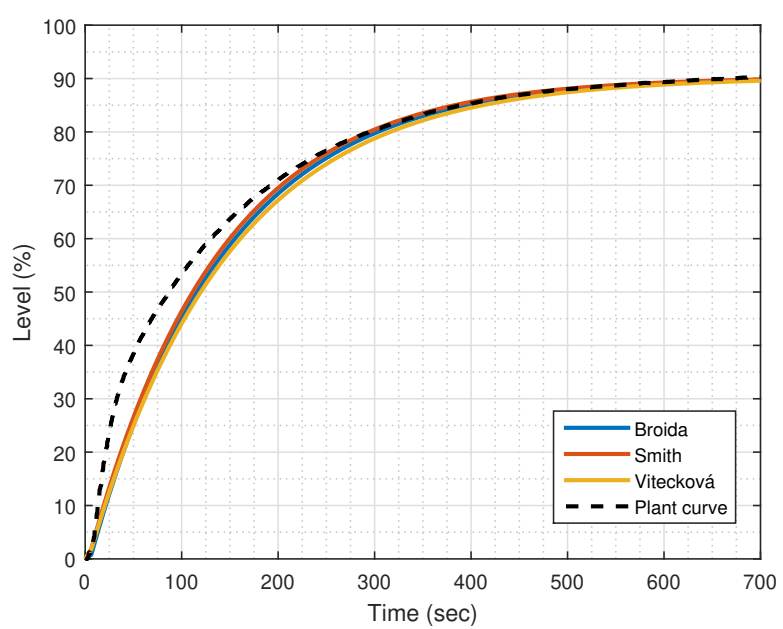

Figure 4: Comparison between the experimental open-loop and the simulation identified responses.

\begin{tabular}{c|c}
\multicolumn{2}{c}{ Table 1: ISE values. } \\
\hline METHOD & VALUE \\
\hline Bröida & $3.0403 \times 10^{4}$ \\
\hline Smith & $\mathbf{2 . 3 3 0 2} \times \mathbf{1 0}^{\mathbf{4}}$ \\
\hline Vitečkovà & $3.6342 \times 10^{4}$ \\
\hline
\end{tabular}

Comparing the results obtained in Table 1, it is noted that the smallest error presented was from Smith's identification method. Therefore, the entire development of the work based on the transfer function shown in (2).

$$
\begin{aligned}
G_{(s)} & =\frac{K}{\tau s+1} e^{-L s} \\
& =\frac{90.31}{133.9 s+1} e^{-3.5 s}
\end{aligned}
$$

where $K$ is the static gain, $\tau$ is the time constant and, $L$ is the transport delay.

\section{Tuning of Classic Controllers}

The control theory is increasingly linked to the computing area, which implies a frequent evolution in control systems for its expansion in the most diverse sectors of the industry. However, despite this growth, many projects are still operating with PID controllers due to their robustness and easy implementation [14]. This, in turn, presents the selection of tuning parameters as the main problem.

The tuning of a controller consists of selecting appropriate values that reach the conditions which will be submitted, which vary according to the type of controller desired and directly depend on the previously 
defined specifications, such as time constants, stabilization time and overshoots.

In some cases where the actuator remains saturated for a long period, the integral term generates undesired overshoots, which can make it unreliable in the industry field.

At this work, it is presented one AWT applied to 5 different types of controllers: Ziegler-Nichols [15], Cohen-Coon [16], Haalman [17] e CHR with $0 \%$ e $20 \%$ of overshoot [18].

\section{Controller Topology with the Anti- Windup Technique}

The AWT used in this work was selected as being the most effective topology according to the research carried out in work [1], illustrated in Fig. 5.

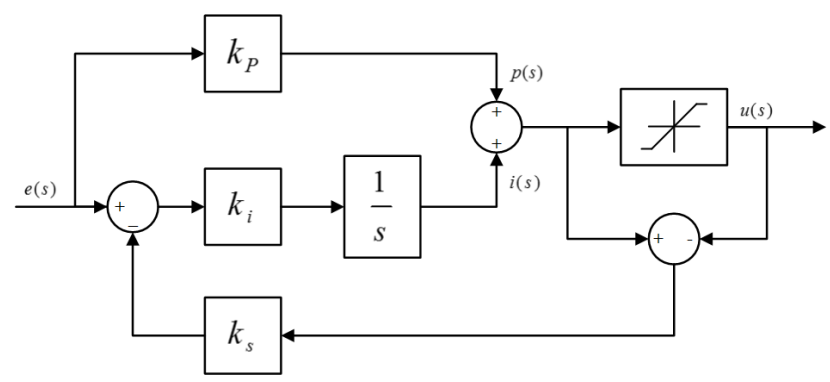

Figure 5: Block diagram of the AWT used [1].

The AWT topology above has a saturation nonlinearity present before the actuator signal in order to create a differential between the control signal and the system output. The device only works when there is saturation, that is, if there is no non-linearity in the actuator, the PI control normally occurs in the system.

The block diagram presented in Fig. 6 was built in Simulink, where " $k_{p}$ " and " $k_{i}$ " are, respectively, the proportional and integral controller gains used, and " $k_{s}$ " is the constant that multiplies the error from saturation, attributed with $1 / \sqrt{\tau}$. This value was the same in all experiments, because it can be related to the system dynamics characteristics, not directly to the controller gains $[19,20]$.

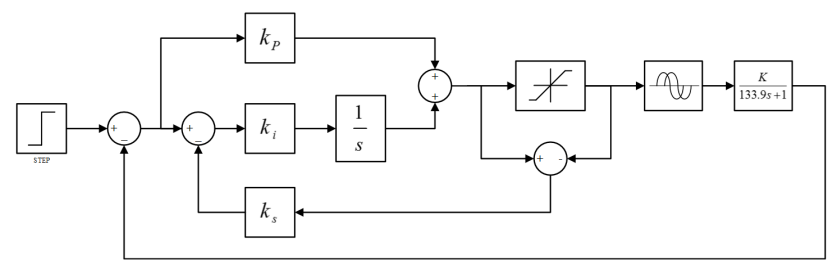

Figure 6: Block diagram applied to the project through Simulink.

\section{Experimental Results}

The experimental results are divided into 2 parts, differing only in the setpoint shapes: Section 5.1 shows the results with only 1 setpoint change using 5 controllers; Section 5.2 presents only the 2 best performance controllers of Section 5.2 but with 2 setpoints changes.

Also, the system transfer function presented in (2) is considered for all simulation tests.

\subsection{Unique Setpoints}

This section presents the experimental tests for the 5 controller tuning methods with only 1 SP change, at the beginning of the test ( $50 \%$ of amplitude). Then, Figs. 7, 8, 9, 10 and 11 illustrate their respective performances. For comparison, they were plotted with and without the AWT presence.

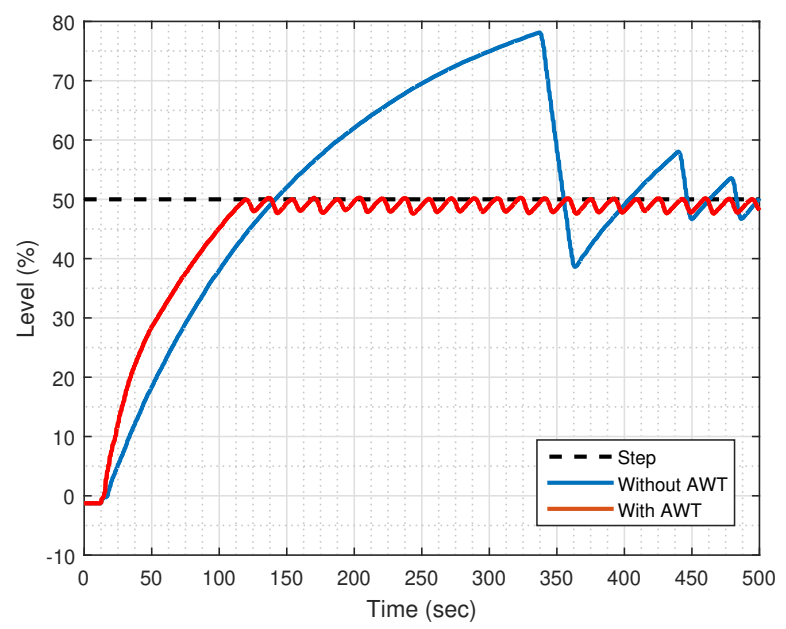

Figure 7: Ziegler-Nichols controlled responses with and without AWT.

From the curves obtained with and without AWTs, the ISE index between them and the input purely applied to the system was calculated (defined to be $50 \%$ of the tank level). The values found are presented in Table 2.

Table 2: ISE index calculated for unique SP experimental tests.

\begin{tabular}{c|c|c}
\hline PI Controllers & With AWT & Without AWT \\
\hline Ziegler-Nichols & $\mathbf{1 . 6 5 8 3} \times \mathbf{1 0}^{\mathbf{5}}$ & $4.0355 \times 10^{5}$ \\
\hline Cohen-Coon & $\mathbf{1 . 6 5 3 3} \times \mathbf{1 0}^{\mathbf{5}}$ & $2.8767 \times 10^{5}$ \\
\hline Haalman & $2.4686 \times 10^{5}$ & $1.9788 \times 10^{5}$ \\
\hline CHR 0\% & $1.7876 \times 10^{5}$ & $1.8476 \times 10^{5}$ \\
\hline CHR 20\% & $1.6873 \times 10^{5}$ & $1.9699 \times 10^{5}$ \\
\hline
\end{tabular}




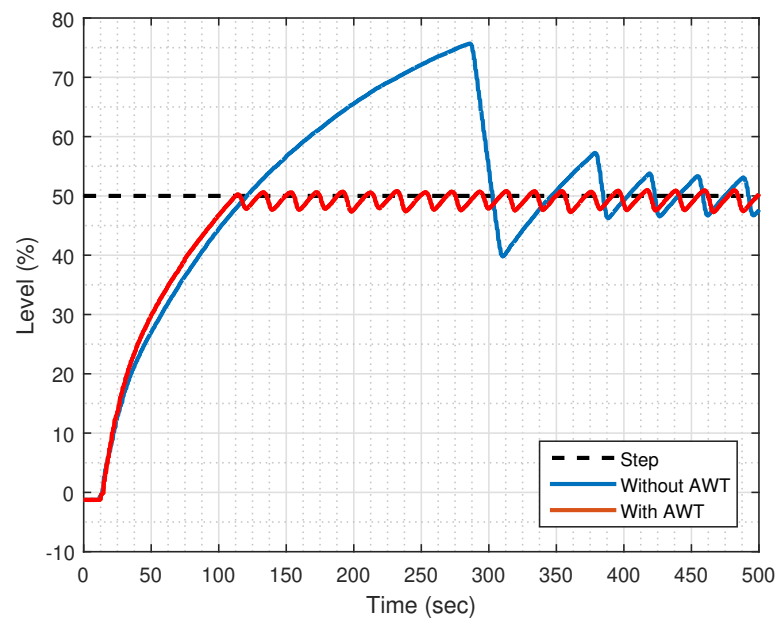

Figure 8: Cohen-Coon controlled responses with and without AWT.

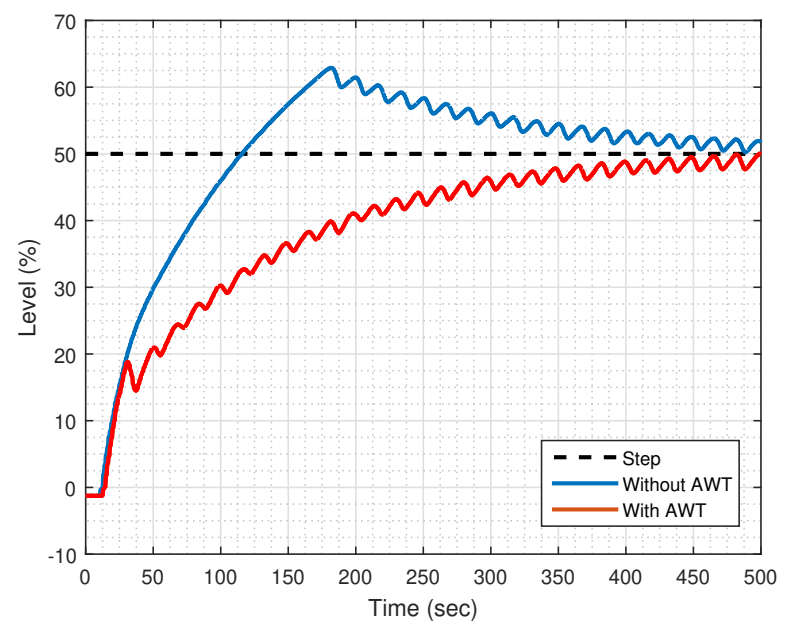

Figure 9: Haalman controlled responses with and without AWT.

\subsection{Multiple Setpoints}

In order to prove the effectiveness of the AWT technique concept, a variable SP was applied in the system, with $40 \%$ at the beginning of the test and $60 \%$ from 250 seconds, considering the two controllers with the best responses presented in Section 5.1.

Therefore, through a brief analysis made of Table 2 , it is noticed that the lowest values are those obtained by the controllers of Ziegler-Nichols and Cohen-Coon. Thus, the results are illustrated in Figs. 12 and 13.

Analyzing these responses, the respective ISE indices are shown in Table 3.

\section{Conclusions}

Analyzing the results obtained in the Table 2, it can be concluded that the controllers of Ziegler-Nichols,

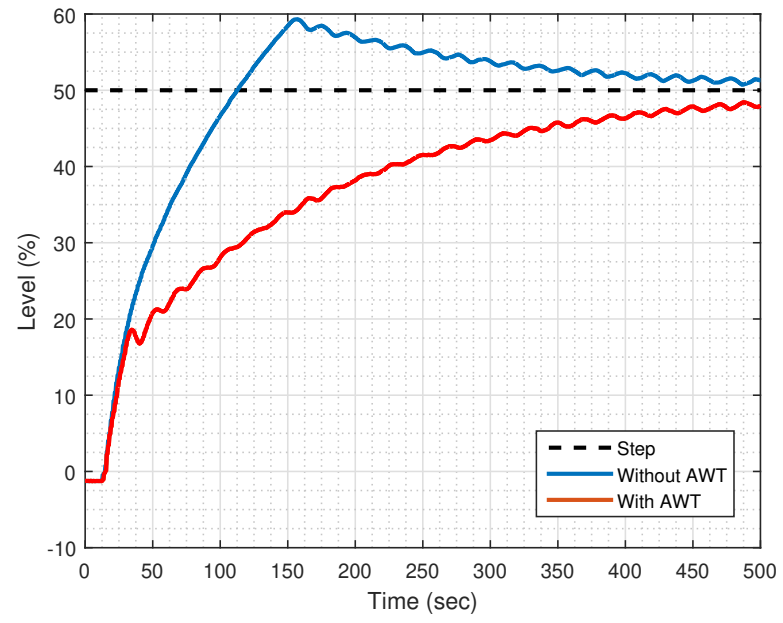

Figure 10: CHR 0\% overshoot controlled responses with and without AWT.

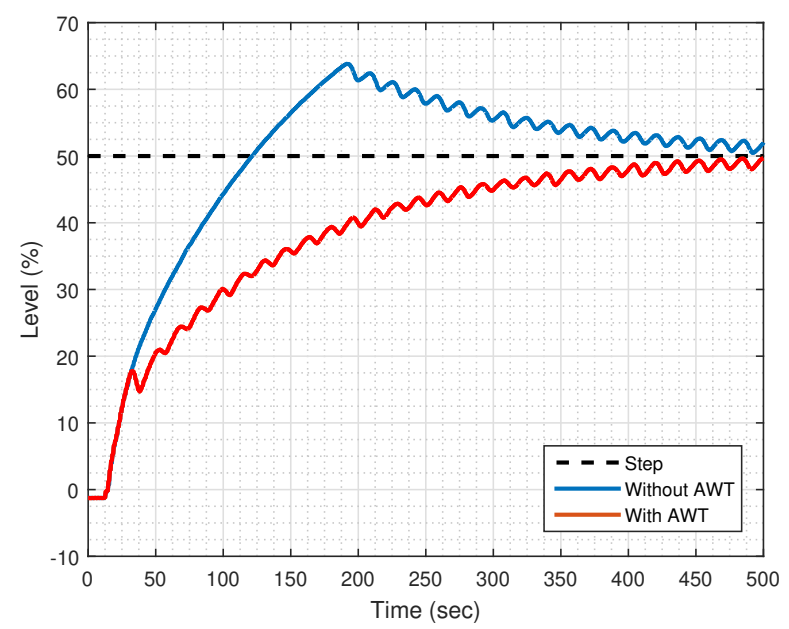

Figure 11: CHR 20\% overshoot controlled responses with and without AWT.

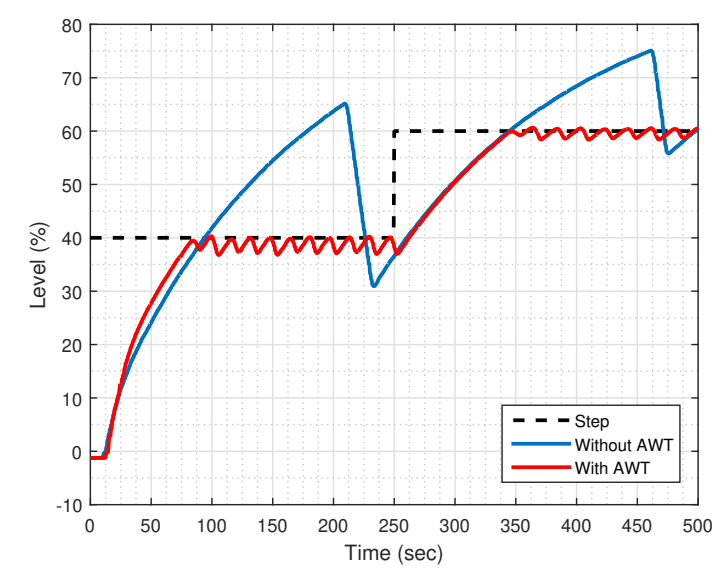

Figure 12: Ziegler-Nichols controlled responses with and without AWT for multiple SPs.

Cohen-Coon, Chien, Hrones and Reswick with 0\% and $20 \%$ overshoot showed less error with AWT when 


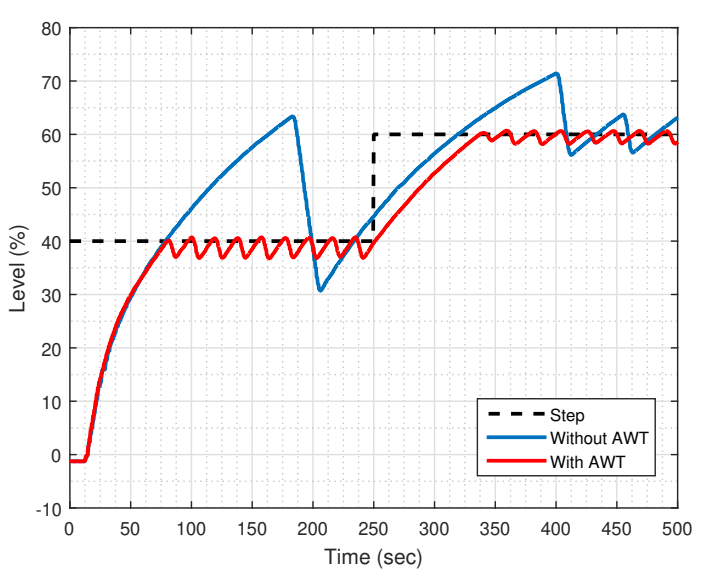

Figure 13: Cohen-Coon controlled responses with and without AWT for multiple SPs.

Table 3: ISE index calculated for multiple SP experimental tests.

\begin{tabular}{c|c|c}
\hline PI Controllers & With AWT & Without AWT \\
\hline Ziegler-Nichols & $1.2669 \times 10^{5}$ & $2.2346 \times 10^{5}$ \\
\hline Cohen-Coon & $\mathbf{1 . 1 1 4 7 \times \mathbf { 1 0 } ^ { \mathbf { 5 } }}$ & $1.6494 \times 10^{5}$ \\
\hline
\end{tabular}

compared to the system without it. With that, it is concluded the AWT topology used for these controllers became effective and useful.

On the other hand, the Haalman controller presented a greater error with the AWT, which can be considered inefficient for this application. However, it does not justify its use, since, although the error was greater with the AWT, there was no overshoot in the system, which can prolong the actuators lifespan. This behavior can also be seen in other controllers, differing only in the ISE index calculated in relation to the desired reference.

Regarding the settling time, it was observed that Ziegler-Nichols and Cohen-Coon controllers presented faster responses when compared to the others, thus being considered even more efficient. In the controllers of Haalman and Chien, Hrones and Reswick with $0 \%$ and $20 \%$ of overshoot, slower responses are noted, which makes them unfeasible depending on their possible application.

Starting from the analysis of the results from the two best controllers to the variable SP, it is possible to conclude through the Table 3, the Cohen-Coon controller proved to be the best one among those tested, presenting the lowest ISE index reported in Tables 2 and 3. Therefore, in view of the aforementioned facts, this controller became the most suitable presented here.

It is also necessary to highlight that it was difficult to maintain a similarity between the simulated and real responses, due to the sensitivity of the actuator present in the plant and another non-linearity intrinsic to the system.

\subsection{Future Works}

Having concluded the best controller for the AWT method in this work, it is also intended, for future applications, the implementation of others AWTs for more results analysis. It is also considered to apply a non-linear identification method for a better approximation, and consequently, other types of controller.

\section{Acknowledgment}

The authors would like to thank CEFET-MG and Leuphana University of Lüneburg for the financial support.

\section{References:}

[1] F. Ferreira, T. Nascimento, M. Santos, N. Bem, and V. Reis, "Anti wind-up techniques applied to real tank level system performed by PI controllers," in 20th International Conference on System Theory, Control and Computing (ICSTCC). IEEE, 2016, pp. 263-268.

[2] C. C. Ko, B. M. Chen, J. Chen, Y. Zhuang, and K. C. Tan, "Development of a web-based laboratory for control experiments on a coupled tank apparatus," IEEE Transactions on education, vol. 44, no. 1, pp. 76-86, 2001.

[3] R. Paull and N. Afroz, "Anti-windup FOPI controller for step motor," in 2nd International Conference on Electronics, Materials Engineering \& Nano-Technology (IEMENTech). IEEE, 2018, pp. 1-4.

[4] A. Shyam and F. D. J L, "A comparative study on the speed response of BLDC motor using conventional PI controller, anti-windup PI controller and fuzzy controller," in International Conference on Control Communication and Computing (ICCC). IEEE, 2013, pp. 68-73.

[5] E. Tomaszewski and J. Jiangy, "An anti-windup scheme for proportional resonant controllers with tuneable phase-shift in voltage source converters," in Power and Energy Society General Meeting (PESGM). IEEE, 2016, pp. 1-5.

[6] J. M. S. Ribeiro, M. F. Santos, M. J. Carmo, and M. F. Silva, "Comparison of PID controller 
tuning methods: analytical/classical techniques versus optimization algorithms," in 18th international Carpathian control conference (ICCC). IEEE, 2017, pp. 533-538.

[7] F. F. Panoeiro, M. F. Santos, D. C. Silva, J. L. Silva, and M. J. Carmo, "PI controller tuned by bee swarm for level control systems," in 19th International Carpathian Control Conference (ICCC). IEEE, 2018, pp. 301-306.

[8] L. C. Gonçalves, M. F. Santos, J. L. da Silva, H. B. Rezende et al., "Development of a PI controller through an ant colony optimization algo-

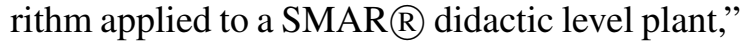
in 19th International Carpathian Control Conference (ICCC). IEEE, 2018, pp. 150-155.

[9] M. V. Garcia, M. F. Santos, C. H. S. Vasconcelos, V. F. Vidal, and M. F. Silva, "Development of an electromechanical positioner with pid controller embedded in a PIC18F4550 microcontroller: A practical validation case study," in 19th International Carpathian Control Conference (ICCC). IEEE, 2018, pp. 277-282.

[10] R. F. Tanda, "Evaluación del desempeño en métodos experimentales de identificación a lazo abierto," Revista de Ingeniería Electrónica, Automática y Comunicaciones, vol. 32, pp. 50-64, 2011.

[11] R. Luus, "Digital computer process control," 1974.

[12] V. Miluše, A. Víteček, and L. Smutnỳ, "Simple PI and PID controllers tuning for monotone selfregulating plants," IFAC Proceedings Volumes, vol. 33, no. 4, pp. 259-264, 2000.
[13] F. F. Panoeiro, M. F. Santos, D. C. Silva, J. L. Silva, and M. J. Carmo, "Pi controller tuned by bee swarm for level control systems," in 19th International Carpathian Control Conference (ICCC). IEEE, 2018, pp. 301-306.

[14] M. Bauer, A. Horch, L. Xie, M. Jelali, and N. Thornhill, "The current state of control loop performance monitoring -a survey of application in industry," Journal of Process Control, vol. 38, pp. 1-10, 2016.

[15] J. G. Ziegler, N. B. Nichols et al., "Optimum settings for automatic controllers," trans. ASME, vol. 64 , no. $11,1942$.

[16] G. Cohen, "Theoretical consideration of retarded control," Trans. Asme, vol. 75, pp. 827834, 1953.

[17] A. Haalman, "Adjusting controllers for a deadtime process," Control Engineering, pp. 71-73, 1965.

[18] K. L. Chien, "On the automatic control of generalized passive systems," Trans. Asme, vol. 74, pp. 175-185, 1972.

[19] C. Bohn and D. Atherton, "An analysis package comparing PID anti-windup strategies," Control Systems Magazine, vol. 15, no. 2, pp. 34-40, 1995.

[20] M. Tharayil and A. Alleyne, "A generalized PID error governing scheme for SMART/SBLI control," in Proceedings of the American Control Conference, vol. 1. IEEE, 2002, pp. 346-351. 